Paideusis

\title{
In A Mindful Moral Voice: Mindful Compassion, The Ethic of Care and Education
}

\section{Deborah Orr}

Volume 21, numéro 2, 2014

Working Compassion

URI : https://id.erudit.org/iderudit/1071565ar

DOI : https://doi.org/10.7202/1071565ar

Aller au sommaire du numéro

\section{Éditeur(s)}

Canadian Philosophy of Education Society

ISSN

0838-4517 (imprimé)

1916-0348 (numérique)

Découvrir la revue

Citer cet article

Orr, D. (2014). In A Mindful Moral Voice: Mindful Compassion, The Ethic of Care and Education. Paideusis, 21(2), 42-54. https://doi.org/10.7202/1071565ar
Résumé de l'article

This paper argues that Carol Gilligan's Ethic of Care has strong affinities with the Buddhist concept of karuna (compassion) which, Jay Garfield has argued, is the necessary foundation of rights theory. Its central argument is that both moral compassion and thus rights theory are grounded in the natural compassionate care a mother exercises in order to promote the flourishing of her child without which children, and consequently adult society, would not survive in any form. Wittgenstein's concept of language-games is brought to bear on Buddhist philosophy to foreground the rootedness of human experience in connection and empathy. This further supports the naturalness of compassionate care, the Ethic of Care and karuna. Finally, mindfulness meditation is proposed as a practice appropriate for the educational context for the development of karuna as a moral resource for personal, civil and professional life. 


\title{
In A Mindful Moral Voice: Mindful Compassion, The Ethic of Care and Education
}

\author{
DEBORAH ORR \\ York University
}

\begin{abstract}
This paper argues that Carol Gilligan's Ethic of Care has strong affinities with the Buddhist concept of karuna (compassion) which, Jay Garfield has argued, is the necessary foundation of rights theory. Its central argument is that both moral compassion and thus rights theory are grounded in the natural compassionate care a mother exercises in order to promote the flourishing of her child without which children, and consequently adult society, would not survive in any form. Wittgenstein's concept of language-games is brought to bear on Buddhist philosophy to foreground the rootedness of buman experience in connection and empathy. This further supports the naturalness of compassionate care, the Ethic of Care and karuna. Finally, mindfulness meditation is proposed as a practice appropriate for the educational context for the development of karuna as a moral resource for personal, civil and professional life.
\end{abstract}

Buddhism in America may be mostly lay Buddhism. The family should become a field of practice, and the Buddhist center should be a center for families to come and practice ... Democracy, science, and art should contribute as well. We should build Buddhism with the local materials. (Thich Nhat Hanh in Fields, 1992, p. 377)

\section{Introduction}

Buddhist mindfulness practice is emerging as the most frequently used form of contemplative education. It currently has a multitude of uses ranging from simple relaxation to enhance focus and concentration, to breaking attachments to habitual ideas and practices, to opening space to allow for the emergence of new, creative actions and ideas (Orr, 2012). This paper will undertake to explore the moral dimension opened up by mindfulness practice by making the argument that, with its focus on karuna (compassion), which is grounded in the complementary notions of sunyata (emptiness), and pratityasamutpada (interconnectedness), Buddhist moral life has strong affinities with both Western pre-modern moral practices and with the contemporary Ethic of Care which Carol Gilligan (1982) has identified.

There are two major reasons for the recognition and incorporation of karuna as an aspect of mindfulness practice in its educational uses. First and foremost is to avoid the distortion, devaluation and misuse of mindfulness practice that has been largely the fate of its mother discipline, Hindu yoga. With its focus on asana practice, which is barely mentioned in Patanjali's classic text, Yoga-Sutra (Hartranft, 2003; see also Boccio, 2004), this vital and complex system of holistic human development has been commoditized and

(C) Copyright 2014. The author, Deborah Orr, assigns to Paideusis the right of first publication and educational and non-profit institutions a non-exclusive license to use this document for personal use and in courses of instruction provided that the article is used in full and this copyright statement is reproduced. Any other usage is prohibited without the express permission of the author. 
thereby reduced to little more than a physical exercise routine. It is, perhaps, worth mentioning that one of the eight limbs of Patanjali's yoga that often gets little attention in Western yoga centers is meditation (dhyana (Skt.), chan (Chin.), zen (Jap.)). While enhancing the student's performance through the use of mindfulness is a valid goal, we will see in what follows that its instrumentalization solely for self-aggrandizement is a gross violation of the spirit and purpose of this practice.

The second broad area which demands attention is that compassion is widely appealed to by Buddhist leaders as the foundation of moral action in addressing a wide range of issues, from overcoming personal suffering, to human rights, to peace work, to environmental issues and beyond (for a representative sample see Kotler, 1996; Nhat Hanh, 1998, 2006; Chapppell, 1999; McLeod, 2006). However, compassion, which calls for an equal and sometimes a primary consideration of others - often of devalued humans, non-humans and even the non-sentient world - may appear to be in conflict with the personal rights valorized by contemporary liberal theory if not simply irrelevant to it. Considering this problem in his "Human Rights and Compassion: Toward a Unified Moral Framework" the Buddhist scholar Jay Garfield (2002) raises the apparent conflict between the Dalai Lama's statements on the one hand that "the demand for human rights is indeed universal in scope, and that to the extent that a culture deprives its citizens of fundamental human rights, that culture is morally deficient" (p. 187), and, on the other hand, that he "has been a consistent exponent of the view that moral life is grounded in the cultivation and exercise of compassion" (p. 188). This grounding in compassion, Garfield asserts, "is the essence of Buddhist moral life" (p. 188; also Dreyfus, 1995; Schroeder, 2001).

Garfield argues that not only need there be no conflict between rights theory and compassion, but that compassion must be seen as foundational to any rights theory incorporating compassion (pp. 189, 204). In gist, Garfield holds that rights are buman ${ }^{1}$ rights, possessed by any person and thus that, as the Dalai Lama has said, any culture that abrogates them is morally deficient. However, in liberal theory there is a mutual entailment between rights and duties in contrast to compassion which fosters benefiting others to whom we have no duties and who have no rights over us. Although some may wish to argue that benefiting others is morally irrelevant, this is not a widely shared view nor, as we will see, a tenable one in some morally significant contexts. Garfield locates a fundamental difficulty for rights theory in the problem that there is no logical reason for anyone to adhere to it; rights are not self-justifying and attempts to advance duty as a reason to adhere to a social contract results in a fatal regress (pp. 195 - 196). He observes that "compassion governs our interactions in a private sphere ... for example, relations between parents and children" (p. 193). This is significant for rights theory, which is designed to function in the public sphere where liberty may be rightly limited, whereas the private sphere was demarcated to provide a realm of freedom of thought and action. The private sphere encompasses not only the areas of ideological thought, religious affiliation, etc. but also the home and it is here, Garfield observes, that compassion is cultivated and utilized and beyond that, it is here that "our moral sensibilities, even thought they are often played out on a more public stage, are cultivated"(p. 196). Consequently, his argument makes compassionate morality the basis for rights theory in the public sphere and holds further that in grounding moral theory in compassion the public/private distinction is undercut. In his words, "neither rights nor incentives can motivate compassionate action. But compassion can certainly provide the motivation for constructing a system of rights, and for the creation of incentives to further compassionate action" (p. 202). The foregoing hardly does justice to Garfield's extended and detailed paper, but it does serve to raise the issues of the nature and role of Buddhist compassion (karuna) and of the relationship between the distinctly Buddhist form of compassion and that practiced within the context of the family.

This paper proposes that the moral orientation that Carol Gilligan has named the Ethic of Care and Responsibility (1982), hereafter the Ethic of Care, while in important ways different from Buddhism and its approach to moral issues, is uniquely positioned to form a powerful synthesis with it. The central argument of this paper is that both moral compassion, and rights theory, are already practically grounded in the natural compassionate care a mother exercises in order to promote the flourishing of her child for without it children,

\footnotetext{
${ }^{1}$ This paper will not address the broader domain of rights which includes animals and the earth although karuna is extended to these.
} 
and consequently adult society, would not survive in any form. Gilligan's work shows that the Ethic of Care is developed out of the natural activities of nurturing and socialization within the family and so utilized in the private sphere. Although women have historically been in the forefront of actions for social change grounded in compassion for the oppressed - the suffrage movement and the movement for the abolition of slavery come to mind - Care is based in and often confined to the familial group and context. In contrast, the Ethics of Rights and Justice is associated with the male and masculinity and dominates the public sphere. Thus Care's ideological connection with the female and femininity and concomitant suppression in the male and masculinity currently limits its development and broader use outside of the family and may also serve to limit its practical relevance to the project Garfield endorses.

In what follows we will begin with a brief review of moral practices in the pre-modern West and the transition to distinctly modern ethical forms such as Kant's Deontology or Mill's Utilitarian Principle which are now thought to be most appropriate to the public sphere. While I may be overdrawing this distinction for heuristic purposes, in order to highlight the difference between moral compassion and ethics in the modern sense, I will work with a distinction between morals, including practices in the pre-modern West which are often designated 'Ethics', as opposed to distinctly modern-era ethical theories which are grounded in the logical abstract formalism developed out of the criteria of scientific investigation and theory. The private/public and morals/ethics distinctions will illuminate the gendered assignments of the Ethic of Care and the Ethic of Rights and their differential valuations which Gilligan's work uncovered. The Buddhist philosopher Nagarjuna's examination of the notion of interconnectedness (pratityasamutpada) and its relationship to compassion (karuna) will then be outlined and Wittgenstein's work on language-games will be brought to bear in order to more fully elaborate the rootedness of human experience in connection and empathy. Finally, I will argue for incorporating karuna as an aspect of mindfulness practice in the classroom in order to develop a moral dimension across the disciplines of formal education.

\section{The Western Context}

It is important to note that, although some Western thinkers are engaged in developing a "Buddhist ethic" (Keown, 2000; Powers \& Prebish, 2009), Buddhism does not have a tradition of 'ethics' in the Western sense of a formal, abstract and universal system of normative principles to govern human conduct. In the West attempts to develop such a system are themselves a recent undertaking developed out of social and cultural changes associated with modernity and, as such, distinct from the major moral approaches of earlier ages. Toulmin's (1990) survey of the development of modern Western ethics has shown that this project emerged with the creation of early modern ideals of a singular rational process as the foundation of the sciences, most especially physics and logic. That conception of "rationality" rapidly gained prestige and influence and came to dominate virtually all areas of human endeavor. Whether art or ethics, politics or technology, "they are held together by one shared thread: a shared conception of rationality, which came to the fore in the $17^{\text {th }}$ century and has dominated much in Western thinking every since." (198).

As scientific method developed in the modern West, mathematics was taken as the language best suited to carry out enquires of all types and thus to arrive at certainty. With reference to Descartes' work on geometry and speaking specifically of early modern developments in logic, in their History of Logic Kneale and Kneale (1962) summarize the view that, "When one proposition follows logically from another, it should be possible to formulate the two propositions in such a way that their relation can be seen to depend on their form alone, that is to say, on their logical structure as opposed to their special subject matter." (p. 384) That is, what a proposition or reasoning process is about is irrelevant, may not even be taken into consideration. It is the form that is of importance. The resulting method of abstract formalism was extended across the disciplines including the development of "ethics" in the modern sense. Thus reason, understood in the sense of abstract rational processes, quickly replaced reasonableness with its capacity to deal with concrete factors, as the valorized mode of dealing with all areas of human life.

Prior to the emergence of $17^{\text {th }}$ century modernity the now displaced 'reasonableness' was the dominant mode of deciding how to deal with life's issues, whether on the personal or more broadly on the social and institutional levels. The Roman Catholic Church, which dominated much of what is now modern Europe, 
addressed issues not by appeal to some one, universal ethical principle, but rather in terms of local customs and morés. To cite Toulmin (1990) again,

Throughout the Middle Ages and Renaissance, clerics and educated laymen understood that problems in social ethics (or "values") are not resolved by appeal to any single and universal "tradition". In serious situations, multiple considerations and coexisting traditions need to be weighed against one another. Until the $17^{\text {th }}$ century . . case ethics . . did not aim to provide a unique resolution of every moral problem: rather, it triangulated its way across unexplored ethical territory, using all the available resources of moral thought and social tradition. (p. 135)

In other words, there was no common "moral tradition" and no universal, formal ethical procedures either until, roughly, the time of Descartes. Rather moral issues were addressed within the context of a multitude of interrelated factors including local traditions and morés. But as rationality became dominant in the newly emerging field of ethics, it also became identified with the dominant sex, class and race and this group became the arbiters of ethical issues. These distinctions, especially that of sex, combined with the private/public distinction that became entrenched during modernity, helped ground the identification of modern ethics (the Ethic of Rights and Justice) with males and to place it in their sphere of domination, the public domain.

Modern ethical theories such as those developed by Kant and Mill were constructed on the assumption of underlying universal principles that was built into the modernist concept of scientific rationality. This concept enjoined thinking that is objective, impersonal and replicable and thus capable of producing the same results by any reasoner. This conceptual model is reflected in Lawrence Kohlberg's influential Moral Development Scale (Kohlberg, 1963a) as the most mature and 'highest' level of reasoning about moral issues. His initial study (1963b) followed 72 boys over a 12-year period. On this basis he theorized that the maturing individual becomes ever more impersonal, abstract and objective in their reasoning as they move through the levels of the scale, which focuses initially on hedonistic motivation, then, as the child matures, on conformity to conventional roles and rules, and, at the final Level, on decision making in terms of purely abstract principles. It is worth noting that he had difficulty finding adequate empirical evidence of individuals who reached that final level.

Carol Gilligan's In a Different Voice: Psychological Theory and Women's Development (1982) provides a critique of Lawrence Kohlberg's Moral Development Scale. She argued that girls' and women's responses in dealing with moral dilemmas were not listened to on their own terms. Thus when evaluated on Kohlberg's Scale they consistently scored at a lower level than their male age-mates and consequently were judged as morally immature. In one study Gilligan presented boys and girls with moral dilemmas such as the Heinz Dilemma: Heinz must decide if he will steal a drug which will save his wife's life, but that he can not afford to buy, from a druggist who is making an exorbitant profit from its sale. Her methodology was to listen to how the boys and girls reasoned, not what conclusion they reached.

The dramatic and telling differences she found in styles of moral thinking varied by gender, which is strongly linked to sex. 11-year old Jake's response was typically masculine and male. He held that "math is the only thing that is totally logical" and thus a moral dilemma is "sort of like a math problem with humans" (p. 26). He assumed that anyone using reason would come to the same conclusion, that Heinz would be morally in the right to steal the drug although this is against the law, since saving a life trumps avoiding theft. Clearly, Jake, in his impersonal use of deductive logic, has developed considerable facility with the use of advanced ethical reasoning and so is well on his way to the upper strata of Kohlberg's Scale.

The logic of 11-year old Amy's deliberations did not adhere to the formal structure mandated by Kohlberg's Scale and thus she scored lower than Jake. Rather than a math problem, Amy saw the dilemma as "a narrative of relationships that extends over time" (p. 28), and its adequate resolution one which would preserve the relationships between Heinz, his wife, and the druggist while avoiding harm to any of them.

Since Amy's moral judgment is grounded in the belief that, 'if somebody has something that would keep somebody alive, then it's not right not to give it to them"', she considers the 
problem in the dilemma to arise "not from the druggist's assertion of rights but from his failure of response. (p. 28)

Amy's treatment of the Heinz dilemma exhibits the hallmarks of the person utilizing the Ethic of Care: $\mathrm{s} /$ he is grounded in a sense of the self as communal and in relationship with others. There is a lack of separation here in contrast to the extreme individualism typical of proponents of the Ethic of Rights and Justice. Emotions supporting care are valued and the moral reasoner, who tends to be co-operative and open, seeks to preserve a sense of community and relatedness. It is this orientation that leads the moral reasoner to seek solutions that preserve relationships and avoid harm in an attempt to support the flourishing of all involved.

The difference in the responses of males and females to moral dilemmas is grounded in their different ways of understanding themselves, their world and the people in it, that is, in socially constructed gender. Gilligan locates the genesis of this difference in their differential experiences during the process of individuation. She grounds her position in Nancy Chodorow's The Reproduction of Mothering (1978) which argues that gender identity is a function of "the asymmetrical organization of parenting, with the mother's role as primary parent and the father's typically greater remoteness and his investment in socialization especially in areas concerned with gender-typing" (p. 166). The individuation process for girls is to remain in a closer relationship with their mothers and to do so longer, whereas boys are encouraged to separate and develop independence. The result for each child is that,

From the retention of preoedipal attachment to their mother, growing girls come to define and experience themselves as continuous with others; their experience of self contains more flexible or permeable ego boundaries. Boys come to define themselves as more separate and distinct, with a greater sense of rigid ego boundaries and differentiation. The basic feminine sense of self is connected to the world, the basic masculine sense of self is separate. (p. 169)

Thus Chodorow concludes that, "Girls emerge from this period with a basis for "empathy" built into their primary definition of self in a way that boys do not" (p. 167).

In treating a moral dilemma involving life and death as "like a math problem with humans" Jake demonstrates a well-developed masculine ego oriented to the Rights and Justice approach. His style of moral decision-making is rational, impersonal and objective; it utilizes 'reason' in the modern sense of the term. He weighs the moral rules (stealing vs. saving a life) to determine the correct course of action. In contrast Amy, who is socialized to the feminine ego-style in which self is understood as relational, employs the Ethic of Care. She uses a narrative logic (Orr, 1995, 1989) which focuses on preserving relationships and individual wellbeing by creating a scenario in which the needs of all involved will be met as fully as possible. She seeks a solution that is 'reasonable'.

As we will see in the next section, it is precisely one's sense of connection with others, identified by modern theorists from Freud to Kohlberg with women's experience and limited to family, but expunged from their reasoning processes by "mature" modern male ethical reasoners, that is the basis for Buddhist morality. The importance of the child's development in the family is alluded to in Thich Nhat Hanh's epigraph to this paper by making "The family . . . a field of practice, and the Buddhist center . . . a center for families to come and practice", for it is in this familial environment that boys in their preoedipal stage, as well as girls, develop a relational ego which remains available to them for moral decision making (Johnson, 1988). The aloof and rational masculine ego, a manifestation of the Hobbesian notion of the 'isolated social atom', which is achieved precisely by the severing of connection, is shown by both Nagarjuna and Wittgenstein to be based on an incoherent concept of the self.

\section{The Relational Self in Nagarjuna and Wittgenstein}

As Thich Nhat Hahn recommended, this section will begin to "build Buddhism with local materials". The $2^{\text {nd }}$ century Indian Buddhist philosopher Nagarjuna will be brought into conversation with the $20^{\text {th }}$ century 
Western philosopher Wittgenstein to develop a synthesis that will enhance the work of both. While they have much in common, they also each have something to contribute to the other; Nagarjuna's work carries with it access to the meditation practices which Wittgenstein lacked for the full realization of his insights, and Wittgenstein brings a close study of the uses of conventional or ordinary language which provides much needed detail to Nagarjuna's philosophical investigations, especially of the nature of the "conventional truths" in which Nagarjuna argues Buddhist wisdom is grounded.

In common, they both hold that their work does not advance any theses, rather it is what could be called a 'therapy for the understanding'. This therapy is carried out through a rigorous analysis of problematic conceptual formations in order to show their incoherence and thus lessen their hold on our thinking and our lives. This is necessary because concepts central to human life and its flourishing, especially the concept of the self, are misunderstood in ways that render them harmful. For Nagarjuna these misunderstandings develop through a person's attachment to and identification with reified ${ }^{2}$ concepts which are held by metaphysicians to have svabhava ${ }^{3}$ or 'self existence', i.e. to be independent, atomistic entities. Most problematic here are those concepts that draw absolute distinctions between the self and all else. For Wittgenstein the problem takes the form of misunderstanding words to have meaning by referring to things that they name, an understanding of language which, his earlier work (1963) showed, also assumes the existence of atomistic entities. For Wittgenstein these conceptual confusions are distortions of legitimate uses of language in conventional language-games. Since language functions in the context of language-games, "the whole, consisting of language and the actions into which it is woven" (1968, \$7), misunderstanding and misusing it negatively affects one's lived experience. In critiquing linguistic misunderstandings, which both philosophers identified as a source of suffering, both strove to bring words back to their ordinary or conventional uses.

Throughout his Mulamadhyamakakarika Nagarjuna tests the logic of reified forms of everyday concepts including 'self (Garfield, 1995, MMK 19). Garfield glosses Nagarjuna's arguments as aimed against, "[t]he hypothesis . . . that over and above (or below or beneath) any composite of phenomena collectively denoted by "I" or a proper name, there is a single substantial entity that is the referent of such a term." (p. 246). He continues that when one grasps that the reified concept of the self is incoherent "one recognizes one's own lack of inherent existence" (p. 247). Ignorance of the sunyata, the lack of an inherent existence or unchanging being (svabhava), of the self is the core suffering-producing delusion and, as long as one clings to it, suffering will persist not only for the self but also for others through the ignorance, ill-will and greed the suffering ego produces. If one is able to, if not entirely stop clinging to the self as an independent entity, at least attenuate that process, then the consequent poisons of the ego will be weakened. However, uses of "I", "me", "mine" are valid in everyday discourse as long as one avoids delusion-producing and logically incoherent reifications. Sunyata, which is usually translated as 'emptiness', is sometimes misunderstood to mean that things are nonexistent but this is true only in the sense that metaphysical entities, i.e. things with svabhava, are non-existent; the existence of things in the everyday sense(s) is not denied. It is important to note that it is not only

\footnotetext{
2 Jay Garfield, in commenting on Nagarjuna's Mulamadhyamakakarika (1990, 307, fn. 10), uses the term "everyday metaphysics" for the "fallacy" of the "person-on-the-street" who, roughly put, tends to reify nouns and give them a quasi-metaphysical status. Although it also can be misleading, I prefer to keep the term "reification" or "everyday reification" because "everyday metaphysics" and committing "fallacies" makes the problem we are trying to address seem much more intellectual and theoretical than it is. Deep-seated human tendencies, for instance the almost insuperable tendency to believe oneself to be immortal, as well as cultural and social ideologies, practices, and institutions may lead one to live as if certain aspects of one's world-picture reflected an objective, reified reality. Consider in this context the world-pictures supportive of sexism, racism, homophobia, and other axes of social differentiation and oppression which are taken to be descriptive of differences pre-given by reality. (see Orr, 2004, 2005, 2007, 2012). Thus an important level of the problem of reification is that it is often more existential, and even instinctual, than intellectual although it has an intellectual dimension and investigating it on that level can be salutary in helping to lessen the plausibility of these reifications.

${ }^{3}$ Scholars of Buddhism use diacriticals with Sanskrit terms but this is being largely abandoned by those writing for a broader audience. I follow the latter practice in this work.
} 
philosophers who reify concepts; we all do this, often unconsciously, in our day-to-day lives. We think and act in a multitude of ways as if "I" am separate from and independent of all else. Thus the process of interrogating the isolated and alienated self, both through philosophical examination and meditation, is an important part of the process of extending karuna, which is grounded in interconnection, to both others and one's self.

Nagarjuna's philosophical method throughout Mulamadhyamakakarika and his goal of returning his readers to the non-deluded uses of language resonate with the work of the mature Wittgenstein (1968) who argued that "Philosophy is a battle against the bewitchment of our intelligence by means of language" (\$109). Language provides a sort of lens through which we view and organize our world (\$114, also 1972) and which, if it is wrongly understood or wrongly constructed, creates a "picture" which holds us captive $(1968, \$ 115)$ and causes us suffering.

Language does not give us a point-by-point reflection of the world. This view, which Wittgenstein critiques and rejects in his mature work, is the commonplace view that the mind is like a mirror that reflects reality; it pictures reality just as it is. But,

When philosophers use a word - "knowledge", "being", "object", "I", "proposition", "name” - and try to grasp the essence of the thing, one must always ask oneself: is the word ever actually used in this way in the language-game which is its original home: - What we [philosophers] do is to bring words back from their metaphysical to their everyday use. (\$116)

Wittgenstein shows that logically those illicit uses result in solipsism and ultimately the reduction of language to nonsense if one assumed Cartesian mind-body dualism, and an incoherent and nihilistic behaviorism if one assumed a strict materialist view of human being. In order to get at their "everyday uses" Wittgenstein frequently looked at how a word is learned. For that he begins with the "primitive" and "pre-linguistic" $(1975, \$ 540-541)$ behaviors into which the words are woven in language-games. For instance, how does a child learn the word 'pain'? "A child has hurt himself and he cries; and then adults talk to him and teach him exclamations and, later, sentences. They teach the child new pain-behaviour". He continues to explain that "the verbal expression of pain replaces crying and does not describe [or name or picture] it" $(1968, \$ 116)$.

This example helps make several important points that are broadly applicable to language acquisition and use. First, and obviously, in this example the role of primitive and pre-linguistic expression is clear. The adults understand and respond to the pre-linguistic child's expression of his pain, his crying, and their response is itself largely non-linguistic. The child in turn understands the adults' response. Second, language is based in interpersonal relationships and natural ways of behaving with others. It is in the context of relationships with others that the child begins to learn the language not only of pain but also the multitude of other language-games of his or her time and place. Third, the uses to which the child puts a word, 'pain' for example, will be shaped by her or his subsequent social experiences. For instance, a boy will learn not only when not to cry, 'big boys don't cry', 'be a man', etc., but when not to express his pain verbally. We need only think of the difference gender socialization makes to the uses this boy will make of his pain language in contrast to the ones his sister will make, or the contrast between what he might tell a friend and what he might express to his psychotherapist. Finally, while learning to use 'pain' is learning to use a concept and thus is typically understood as an activity of the mind, Wittgenstein's example demonstrates how arbitrary the distinction between mind ('pain') and body (pain) really is. In this example, where does pain leave off and 'pain' begin?

As we see, Wittgenstein's use of 'language-games' (1968 \$7, passim) stresses the embeddedness of language in human behaviors and activities and most especially in human interrelationships and so, as Gilligan and Chodorow theorize, shows that the identity of both young boys and young girls is inherently relational. The relational nature of human life in Wittgenstein's work resonates in important ways with the concept of pratityasamutpada in Nagarjuna's (see also Thurman, 1980). This term is usually translated as 'dependent coorigination' or 'dependent co-arising' and makes reference to the interrelatedness or interbeing of all things. At this point we can note that the range of Nagarjuna's concept of pratityasamutpada is wider than Wittgenstein's as it encompasses all things, whereas a child newly acquiring language experiences its interrelatedness in a much more limited scope. Thus the broadening out of the connectedness that grounds 
the compassion which Garfield (date) sees coming into play on the public stage (p. 196) must be a later, cultivated, understanding. Below we will see that mindfulness can play a powerful part in this cultivation.

Nagarjuna's grounding of meaning in everyday discourse and his rejection of metaphysical uses of terms is made explicit in MMK 24: 18 - 19, verses that Jay Garfield calls "the climax of the entire text" and 'the entire text in embryonic form' (1995, p. 304). There Nagarjuna holds that, "Whatever is dependently coarisen [pratityasamutpada],/That is explained to be emptiness [sunyata]./That, being a dependent designation [i.e. sourced in conventional uses of language],/Is itself the middle way [Madbyamika] (MMK 24:18)." He continues in MMK 24:19 that non-dependently arisen things, and consequently nonempty things, do not exist.

The conventional uses of language are the ordinary, non-reified uses of language. Clarity about these ordinary uses of language, and the human experiences in which they are embedded, is necessary in order to grasp and live out sunyata, or, more correctly, to be sunya. Along with that emptiness, the flip side of it so to speak, is the myriad ways in which we understand our world and ourselves to be interrelated (pratityasamutpada). This is the main point of verse 19 above, that we can only speak with sense of dependently arisen things (pratityasamutpada), things that are in relationship with other things. Any other use falls into one of the logical incoherencies Nagarjuna distinguished (see MMK1:1, passim). And, because nothing has an eternal, unchanging essence (svabhava), the impermanence (anitya) of all things, including the self (anatta) is entailed. For Nagarjuna, as for Wittgenstein, these are not statements of a 'position' or 'theory'; they are reminders of conceptual grammar, that is, of the rules of valid uses of language. They are moves in the philosophical 'therapy of the understanding' game alluded to above. In sum, Nagarjuna is not ruling out the ordinary, every-day uses of language, nor is he revealing to us hitherto unrealized "facts" such that all is "illusion". What is illusory is the metaphysical houses of cards and castles of sand we build with our language. ${ }^{4}$ His project, like Wittgenstein's, is to return us to those unproblematic and non-toxic uses.

\section{Education, Mindful Meditation and Karuna}

To summarize so far, by revealing the structure of the feminine relational ego and the role of empathy in its mode of moral problem solving, the work of Chodorow and Gilligan goes some way toward grounding a moral orientation in a self-concept which avoids the isolation of the purely rational ego of the Rights and Justice approach. Following Toulmin we have identified the modern concept of rationality and its role in modern-era ethical theories as a development out of materialistic science and not as naturally emergent in those who have achieved intellectual maturity. Further, both Nagarjuna and Wittgenstein have argued that the atomized self assumed by the Ethic of Rights is logically incoherent and both have situated the self in relationship. The Western, white, educated male ego has been modeled on the ideal of the atomized self and consequently has, if not lost then greatly inhibited, the possibility of a personal morality grounded in connection and empathy as well as the will to create social structures and institutions on that basis.

The most profound implication of the work of both Nagarjuna and Wittgenstein is the radical constructedness of human being. While this has become something of a cliché in both academic and popular thought, especially with reference to gender (Fine, 2010), its implications have not been fully worked out in the West. However, this work has a long history in Buddhist cultures. David Loy has argued that taking seriously that consciousness is radically constructed and that, in common with our bodies, it is impermanent is the fundamental psychological and spiritual challenge revealed by Buddhism. He holds that the sunya or "lack-of-self", i.e. the radically constructed and so impermanent nature of human being, is the fundamental repression that the major psychological theories of the West have failed to recognize (Loy, 1982). Meditation practices such as mindfulness, combined with study ${ }^{5}$, can begin to counter this repression and to develop an experiential understanding of pratityasamutpada. This means that one must live that understanding, not simply cognitively recognize it.

\footnotetext{
${ }^{4}$ Charles Taylor provides some useful, Wittgensteinian-oriented explorations of the boundaries of conceptual sense. See especially the papers in Philosophical Arguments (1997) and "Theories of Meaning" (1980).

5 Abe (1985) and Thurman (2006) stress both the need for the study of texts its place in traditional practices.
} 
Loy argues that attempting to avoid the sense-of-lack has had profound personal and cultural implications. He has extended his analysis to contemporary Western culture to show how our central cultural concerns - individualism, freedom, capitalism, progress, etc. - are manifestations of the failure to realize that "[our] sense-of-lack is the shadow of [our] sense of self" $(2002,214)$; it is clinging to the reified self that gives rise to the (repressed) fear that it isn't really real. Thus on a personal level this failure plays out in the pursuit of money, sex, fame, power, war (Loy, 2008) and all the other personal obsessions that are pursued in order to fill up that sense-of-lack and so make us feel 'really real'. The cultural and the personal obsessions we are in thrall to are manifestations of the futile attempt to avoid, or repress, the existential sense-of-lack by strengthening the very thing that brings it into being, the reified sense-of-self or ego. Loy (2002) continues,

I am groundless and ungroundable insofar as delusively feeling myself to be separate from the world; but I have always been fully grounded insofar as I am nondual with the world. It turns out that my lack is a lack only as long as I dread it and attempt to fill it up. When I cease doing that, it can be experienced as the source of my creative energy, which wells up from a fathomless source.

According to Buddhism, such awakening is spontaneously accompanied by compassion for all beings, now perceived as part of myself. (p. 214)

Living, in ways consonant with pratityasamutpada is living karuna, a concept whose meaning is well captured by its translation into English as 'compassion'. This English word is drawn from the Latin roots com meaning with, together; and patior, to undergo, bear or suffer, thus 'to experience together', as one. Karuna reminds us that, since we are interconnected, what is done to others, whether human or non-human, is done to oneself and vice versa. Amongst the important implications of karuna is that, while it has strong affinities with the communal ego style that undergirds Gilligan's concept of an Ethic of Care, in contrast to the modern ideal of femininity, the experience this concept points to does not confine empathy to one's immediate family or even one's broader social group. When, or perhaps more correctly for most of us if, pratityasamutpada is fully realized it will have broken down self/other dualisms, be they familial, social or nonhuman.

As noted above, many women take their moral orientation into action outside of the home and family. And both the day-to-day practices of many men, as well as Kohlberg's inability to generate more than a few examples of people who use modern forms of ethics, strongly suggests that men do this as well. This is supported by Johnson's (1988) finding that boys are as capable of generating Care responses to moral dilemmas as are girls although their process of socialization to be men inhibits this. The work of David Forbes teaching inner-city boys to meditate in the context of teaching them to play football "in da zone" gives a promising example of the efficacy of mindfulness in helping young men to develop a selfunderstanding that enables them to begin to loosen the hold of conventional masculinity in their lives and to develop more caring responses to others. Forbes (2002) sums up that,

football was a good place to initiate their quest for the zone. They learned to be mindful of what was going on with themselves and to attend to the moment. They began to see how the mind works and how it can evolve. They found some peace of mind and a sense of mastery when they let themselves be. (p. 204)

The foregoing evidence provides a solid grounding for Garfields's argument that not only is compassion necessary to moderate the potential for abuse inherent in the morally blind application of rights theory, its natural expression is developed by boys as well as girls in the home and can be extended beyond it by them. As well, the naturalness of the compassionate response enables us to see the development of Buddhist karuna as a broadly human possibility, rather than an esoteric or 'mystical' experience open to only the few. It also goes some way to addressing the concerns of those who may believe teaching it is a form of religious indoctrination.

Developing a compassionate orientation in students can begin with the classroom practice of mindfulness. Vipassana or mindfulness practices are possibly the most ancient forms of contemplative practices known and the most widely utilized Buddhist practices in Western classrooms today. Speaking of 
vipassana meditation the prominent teacher and researcher Jon Kabat-Zinn (1994) has said that it is "simple but not easy" (pp. 8-9). It trains one to develop careful but non-judgmental moment-to-moment awareness of experience and to make finely nuanced discriminations of all aspects of any given experience, - somatic, cognitive, emotional, behavioral. One comes to realize on an experiential level, rather than simply on a cognitive level, that all experience is fleeting, transitory, and ill-defined (anitya). With this practice, over time, the concepts through which we define ourselves and distinguish ourselves from others lose their aura of necessity, permanence and immutability and give way to the experience of emptiness (sunyata) or nonreification and thus open space for action through karuna. Importantly, at this level gender identity, along with the other categories of social Othering, is experienced as sunya and so not something to which one will cling. Consequently, karuna is not only theoretically but in practice as open to males as it is to females.

To act well with karuna calls for skillful action, or skill-in-means, (upaya-kausalya) which, as Schroeder (2001) explains, is the link between wisdom (prajna, the recognition of the sunyata of all things) and compassion "which arises from the idea that wisdom is embodied in how one responds to others, rather than an abstract conception of the world" (p. 3). However, this is not a matter of somehow just naturally knowing what to do. It also calls for training and knowledge. Garfield's discussion provides a good example of this; developing compassion by itself will not be sufficient to regulate the public sphere, certainly not in an imperfect world of less than fully enlightened beings pursuing their own self-interest. Thus compassion may be developed to underlay and guide rights theory to meet the needs and ensure the thriving of all beings, but this calls for knowledge not only of rights theory but of the conditions and circumstances in which it will be applied effectively.

Buddhist thought provides a world-picture, or conceptual framework, radically different from the prevailing materialist model of contemporary Western culture. Used in conjunction with a classroom mindfulness practice, the study of the philosophy of Buddhism, and other intellectual texts associated with it can be salutary for interrogating the materialist world-view and rationalist methodology of the modern West and those areas world-wide that these are rapidly colonizing. At its heart the Buddhist non-materialist worldview incorporates the recognition of the holism of human beings and the world of which humans are a part (pratityasamutpada). As David Loy $(1982,2002,2008)$ has shown, these insights can be fruitful when brought to bear on contemporary Western lives and issues.

Developing this alternative view and bringing it to bear to address a wide range of issues has been the work of many peace and environmental activists. A focus on this work can provide examples of areas of academic study where karuna can play a significant role in addressing the intersecting issues of consumerism, environmentalism and social justice. However Thich Nhat Hanh, the Vietnamese Zen master and founder of the Engaged Buddhist Movement, stresses that addressing these issues must begin with individual change. In his speech to the U.S. Congress he reminds its members of the importance of bringing mindfulness practice to the national level. But he also advises that, "we should bring a spiritual dimension into our daily life" (Nhat Hanh, 2006, p. 136). Only thus will we be able to effectively address a problem such as consumerism and the damage it does to the environment.

When we are able to touch joy by living with compassion and understanding, we don't need to over-consume and we don't need to destroy our environment any more. Consuming in this new way, we can preserve the compassion and understanding in us. (p. 137)

Thus, even working with the most wide-ranging issues, Buddhist action begins with individual change and then works to widen that change to others and to the world. Compassion is the ground from which this change springs, but skillfulness in dealing with these issues, as with so many others, requires the disciplinary knowledges and techniques that can effectively be utilized to address these complex problems. Thus mindfulness in, for example, a course in environmental studies, can both deepen the student's compassionate relationship with the nonhuman world and also open up space for the emergence of new and creative ways of addressing the problems we have created there. As David Loy (2008) has strikingly put it, "Understood properly, our taking care of the earth's rainforests is like me taking care of my own leg" (p. 109). We and our world flourish or fail to flourish together. 
It is beyond the scope of this paper to develop a detailed plan for using mindfulness in the educational context. In fact, the needs of particular classrooms and levels of study will differ and so teachers will need to develop their own plans. The rapidly growing body of literature giving examples of how some educators are doing this (Miller et al, 2005; Orr, 2012; Gunnlaugson, O. et al, 2014), along with journals, websites (Orr, 2013), conferences and workshops will also provide useful resources. An important point to be made here is that teachers who wish to utilize mindfulness should have a developed personal practice on which to base it. Finding fora for obtaining this is also becoming increasingly easy with the development of local sangas, visiting teachers and a wide range of online, electronic and print resources. Above I have alluded to just a few examples and must leave it to each reader to access material and develop pedagogies that meets the needs of their students.

\section{Conclusion}

This paper has argued that Carol Gilligan's research has shown that empathic, compassionate care is natural in the mother-child relationship. This has been supported by the work of Nagarjuna and Wittgenstein both of whom show, from very different times and cultural contexts, that humans are relational beings and that care is an integral part of healthy relationships. Thus it has been argued that natural care can be deepened and widened through the use of mindfulness practice into Buddhist karuna. This, in turn, can serve as a moral grounding in contexts beyond the family and even the human. It has been further argued that compassion by itself is not adequate to deal with many of the complex issues with which we are faced on either the personal or the broader socio-cultural level. These call for both thoughtfulness and often for specific disciplinary knowledges and techniques.

Carol Gilligan has described a narrative style of reasoning which is utilized by practitioners of the Ethic of Care. This enables the generation of solutions that, as far as possible, avoid harm and promote the flourishing of all affected by any decision to act. However, the deliberations of the women interviewed for her Abortion Study (1982, pp. 65 - 105) show that this process is not an easy one, nor does it guarantee clear or "correct" decisions. Unlike 11-year-old Jake's "math model", decisions are neither simple nor certain. This demands responsibility for one's conclusions and actions in a way that is not the case were one to use one of the formulae provided by modern ethical theories. This point needs to be emphasized in order to avoid taking compassion as a panacea or as a romanticized approach. Rather, its exercise demands humility and caution. That having been said, the practice of karuna/compassion opens the possibility of actions that are more fully in concert with human nature and respectful of our place in the broader scheme of things. Mindfulness as a simple but powerful technique to promote karuna/compassion can be easily integrated into classrooms at all levels to develop natural compassion and bring it to bear on the full range of curricular, social and environmental issues.

\section{References}

Masao, A. (1985). Zen and Western thought. W. R. LaFleur (Ed.). Honolulu: University of Hawaii. Boccio, F. J. (2004). Mindfulness yoga: The awakened union of breath, body, and mind. Boston, MA: Wisdom. Chappell, D.W. (Ed.). (1999). Buddhist peacework: creating cultures of peace. Boston, MA: Wisdom.

Chodrow, N. (1978). The reproduction of mothering: Psychoanalysis and the sociology of gender. Berkeley, CA: University of California.

Dreyfus, G. (1995). Meditation as ethical activity. Journal of Buddhist Ethics, 2, 28 - 54. http://www.buddhistethics.org/2/dreyfus.txt

Fields, R. (1992). How the swans came to the lake: A narrative history of Buddhism in America (3 $3^{\text {rd }}$ ed.). Boston \& London: Shambhala.

Fine, C. (2010). Delusions of gender: How our minds, society, and neurosexism create difference. New York, NY: W.W. Norton \& Company.

Forbes, D. (2002). Boyz 2 Buddhas: Counseling urban high school male athletes in the zone. New York, NY: Peter Lang. 
Garfield, J. L. (Trans. \& Ed.). (1995). The fundamental wisdom of the middle way: Nagarjuna's Mulamadhyamakakarika. New York, Oxford: Oxford University.

Garfield, J. L. (2002). Empty words: Buddhist philosophy and cross-cultural interpretation. Oxford: Oxford University. Gilligan, C. (1982). In a different voice: Psychological theory and women's development. Cambridge: Harvard University.

Gunnlaugson, O., Sarath, E.W., Scott, C. and Bai, H. (Eds.). (2014). Contemplative learning and enquiry across the disciplines. New York, NY: SUNY.

Hartranft, C. (Trans. \& Ed.). (2003). The Yoga-Sutra of Patanjali. Boston: Shambhala.

Johnson, K. (1988). Adolescents' solutions to dilemmas in fables: Two moral orientations-two problem solving strategies. In C. Gilligan, J. V. Ward, J. McLean Taylor with B. Bardige (Eds.), Mapping the moral domain: A contribution of women's thinking to psychological theory and education (pp. 49 - 71). Cambridge, MA: Center for the Study of Gender, Education and Human Development, Harvard University Graduate School.

Kabat-Zinn, J. (1994). Wherever you go, there you are: Mindfulness meditation in everyday life. New York, NY: Hyperion.

Keown, D. (Ed.). (2000). Contemporary Buddhist ethics. London \& New York: RoutledgeCurzon.

Kneale, W \& Kneale, M. (1962). The development of logic. Oxford: Clarendon Press.

Kohlberg, L. (1963a). The development of children's orientation towards a moral order: Sequence in the development of moral thought. Vita Humana, 6, $11-33$.

Kohlberg, L. (1963b). Moral development and identification. In Stevenson, H., (ed.). Child psychology, 1962 yearbook of the national society for the study of education. Chicago: University of Chicago, $277-332$.

Kotler, A. (Ed.). (1996). Engaged Buddhist reader. Berkeley, CA: Parallax.

Loy, D. R. (1982). Avoiding the void: The lack of self in psychotherapy and Buddhism. The Journal of Transpersonal Psychology, 24(2), $151-179$.

Loy, D. R. (2002). A Buddhist history of the west: Studies in lack. Albany, NY: State University of New York.

Loy, D. (2008). Money, sex, war, karma: Notes for a Buddhist revolution. Boston, MA: Wisdom.

McLeod, M. (Ed.). (2006). Mindful politics: A Buddhist guide to making the world a better place. Boston: Wisdom.

Miller, J., Karsten, S., Denton, D., Orr, D., Kates I. (Eds.). (2005). Holistic learning and spirituality in education: Breaking new ground. New York, NY: SUNY.

Nhat Hanh, T. (1998). The heart of the Buddha's teaching: Transforming suffering into peace, joy and liberation. New York, NY: Broadway.

Nhat Hanh, T. (2006). We have the compassion and understanding. In M. McLeod (Ed.), Mindful politics: $A$ Buddhist guide to making the world a better place (pp. 129 - 138). Boston: Wisdom.

Orr, D. (1989). Just the facts ma'am. Informal Logic, 11(1), 1 - 10.

Orr, D. (1995). On logic and moral voice. Informal Logic, 17(3), 347 - 359.

Orr, D. (2004). The uses of mindfulness in feminist anti-oppressive pedagogies: Philosophy and praxis. Canadian Journal of Education, 27(4), 477 - 498.

Orr, D. (2005). Minding the soul in education: Conceptualizing and teaching to the whole person. In J. Miller, S. Karsten, D. Denton, D. Orr, I. Kates (Eds.), Holistic learning and spirituality in education: Breaking new ground (pp. 87 - 100). New York, NY: SUNY.

Orr, D. (2007). The mind/body paradigm crisis and a new paradigm for feminism. In D. Orr, D. Taylor, E. Kahl, K. Earle, C. Rainwater, \& L. L. McAlister (Eds.), Feminist politics: identity, difference and agency (pp. 15- 40.). Maryland: Rowman \& Littlefield.

Orr, D. (2012). Thinking outside the academic box: an introduction to mindfulness meditation for education. Other Education, Inaugural Edition, 1(1), 79 - 91. http://www.othereducation.stir.ac.uk/index.php/OE

Orr, D. (2013). Mindfulness and contemplative education website. http://www.contemplativeeducation.ca

Powers, J. and Keown, D. (Eds.). (2009). Destroying Mara forever: Buddhist etbics essays in honor of Damien Keown. Ithaca, NY: Snow Lion.

Schroeder, J.W. (2001). Skillful means: The heart of Buddhist compassion. Honolulu, HI: University of Hawai'i.

Taylor, C. (1995). Philosophical arguments. Cambridge, MA: Harvard University Press.

Taylor, C. (1980). Theories of meaning. Proceedings of the British Academy, LXVI, $283-327$.

Thurman. R.A.F. (1980). Philosophical nonegocentrism in Wittgenstein and Chandrakirti in their treatment of the private language problem. Philosophy East and West, 30(3), $321-337$. 
Thurman. R. A. (2006). Meditation and education: India, Tibet and modern America". Teachers College Record, 108(9), $1765-1774$.

Toulmin, S. (1990). Cosmopolis: The bidden agenda of modernity. Chicago, IL: University of Chicago.

Wittgenstein, L. (1961). Tractatus logico-philosophicus. (D.F. Pears \& B.F. McGuinness, Trans.). London: Routledge \& Kegan Paul.

Wittgenstein, L. (1968). Philosophical investigations. (G.E.M. Anscombe, Trans.) Oxford: Basil Blackwell.

Wittgenstein, L. (1972). On certainty. D. Paul \& G.E.M. Anscombe (Eds.). (G.E.M. Anscombe \& G.H. von Wright, Trans.). New York, NY: Harper \& Row.

Wittgenstein, L. (1975) Zettel. G.E.M. Anscombe \& G.H. von Wright (Eds.). (G.E.M. Anscombe, Trans.). Berkeley \& Los Angeles: University of California Press.

\section{About the Author}

I am an Associate Professor in the Department of Humanities at York University. My discipline is philosophy. My current academic interests lie in the pedagogical uses of mindfulness and the philosophical study of mindfulness and morality and especially in the relevance of Wittgenstein and Nagarjuna to these areas. My email is dorr@yorku.ca and my web page is www.yorku.ca/human/faculty/orr.html. I have launched a website for contemplative education - http://www.contemplativeeducation.ca - which you are invited to join for exchange and collaboration with others who are exploring this exciting new pedagogy. 